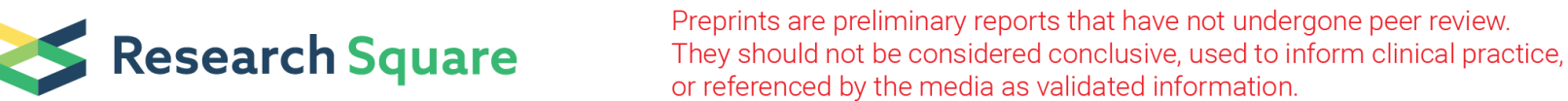

\section{D-Cystine di(m)ethyl Ester Reverses the Deleterious Effects of Morphine on Ventilation and Arterial Blood Gas Chemistry While Promoting Analgesia}

\section{Ben Gaston}

Indiana University School of Medicine Indianapolis

Santhosh M. Baby

Galvani Bioelectronics, Inc

Walter J. May

University of Virginia School of Medicine

Alex P. Young

University of Virginia School of Medicine

Alan Grossfield

University of Rochester Medical Center

James N. Bates

University of lowa Hospitals and Clinics

James M. Seckler

Case Western Reserve University

Christopher G. Wilson

Loma Linda University

Stephen J. Lewis ( $\nabla$ sjl78@case.edu )

Case Western Reserve University

\section{Research Article}

Keywords: D-Cystine, morphine, chemistry, analgesia

Posted Date: March 17th, 2021

DOI: https://doi.org/10.21203/rs.3.rs-294428/v1

License: (c) (1) This work is licensed under a Creative Commons Attribution 4.0 International License.

Read Full License 


\section{Abstract}

We have identified thiolesters that reverse the negative effects of opioids on breathing without compromising analgesia. Here we report the effects of D-cystine diethyl ester (D-cystine diEE) or D-cystine dimethyl ester (D-cystine diME) on morphine-induced changes in ventilation, arterial-blood gas chemistry, A-a gradient (index of gas-exchange in the lungs) and analgesia in freely moving rats. Injection of morphine (10 mg/kg, IV) elicited negative effects on breathing (e.g., depression of tidal volume, minute ventilation, peak inspiratory flow, and inspiratory drive). Subsequent injection of D-cystine diEE (500 $\mathrm{mmol} / \mathrm{kg}, \mathrm{IV}$ ) elicited an immediate and sustained reversal of these effects of morphine. Injection of morphine $\left(10 \mathrm{mg} / \mathrm{kg}\right.$, IV) also elicited pronounced decreases in arterial blood $\mathrm{pH}, \mathrm{pO}_{2}$ and $\mathrm{sO}_{2}$ accompanied by pronounced increases in $\mathrm{pCO}_{2}$ (all indicative of a decrease in ventilatory drive) and A-a gradient (mismatch in ventilation-perfusion in the lungs). These effects of morphine were reversed in an immediate and sustained fashion by D-cystine diME (500 mmol/ $\mathrm{kg}$, IV). Finally, the duration of morphine ( 5 and $10 \mathrm{mg} / \mathrm{kg}$, IV) analgesia was augmented by D-cystine diEE. D-cystine diEE and D-cystine diME may be clinically useful agents that can effectively reverse the negative effects of morphine on breathing and gas-exchange in the lungs while promoting analgesia.

\section{Introduction}

Opioids are given for pain relief in humans and animals but their ability to depress breathing and gas exchange in the lungs is often problematic to the patient. ${ }^{1-5}$ Competitive opioid receptor antagonists such as naloxone and naltrexone can overcome opioid-induced respiratory (OIRD) but they also reverse the analgesia and sedation elicited by opioids so that their clinical value is limited in many instances such as in the operating room and in post-operative sites where pain relief and sedation are essential to the patient. ${ }^{1-5}$ Despite the urgent need to develop drugs that reverse OIRD by mechanisms other than antagonism of opioid receptors, a recent review ${ }^{5}$ concluded that none of the currently available experimental drugs are adequate for therapeutic use in OIRD for a variety of important reasons including that they only minimally improve arterial blood-gas (ABG) chemistry and that all of the drugs need further study of efficacy and toxicity.

Trivedi and colleagues ${ }^{6}$ provided compelling evidence that morphine induces addiction via causing redoxbased changes in global DNA methylation and retrotransposon transcription via morphine-induced inhibition of excitatory amino acid transporter type 3 (EAA3)-mediated cysteine uptake into cells. In addition, Trivedi and Deth ${ }^{7}$ proposed pharmacological strategies including administration of N-acetyl-Lcysteine (which elevates intracellular cysteine levels) to reverse the redox-based epigenetic status of drug addiction. Although there was no evidence that blockade of L-cysteine entry into cells has a role in the expression of OIRD, we reasoned that administration of drugs that bypass the EAA3 may overcome OIRD if this indeed is the major mechanism that needs to be overcome. The class of compounds we have focused upon are the ethyl ester and methyl ester versions of reduced and oxidized thiols (disulfides), which are known to rapidly enter cells including neurons in the brain upon systemic administration. ${ }^{8-21}$ 
Our initial publication ${ }^{21}$ reported that systemic injection of L-cysteine ethyl ester (L-CYSee) reversed the negative effects of morphine on ABG chemistry and Alveolar-arterial (A-a) gradient (index of gas exchange in the lungs) anesthetized rats only when the rats had a tracheotomy. Since L-cysteine itself was inert, we assumed that the biological activity of L-CYSee was due to its intracellular entry and initiation of redox-related processes. It appears that the ability of L-CYSee to reverse the negative effects of morphine on breathing and gas-exchange are overridden by the negative effects on the upper airway including collapse of the tongue over the airway. ${ }^{21}$

Accordingly, we have begun to explore whether D-isomers of cysteine and cystine esters show positive effects against OIRD without the negative effects of the L-isomers, in the hope that (i) the intracellular mechanisms of action of thiolesters are not dependent on stereoselective processes whereas the negative effects of the L-isomers are due to them entering into metabolic pathways that $\mathrm{D}$-isomers cannot. We report here the effects of D-cystine ethyl ester (D-cystine diEE) and D-cystine methyl ester (Dcystine diME) on the actions of morphine in freely moving adult male Sprague-Dawley rats. These Lisomers of these thiolesters rapidly enter cells and exert a variety of metabolic effects ${ }^{8-16}$ but we have not found publications regarding the bioactivity of the D-isomers. We report that systemic injection of Dcystine diEE or D-cystine diME elicits a rapid and sustained reversal of the negative effects of morphine on ventilatory parameters, A-a gradient and ABG chemistry whereas it augmented the analgesic actions of the opioid agonist. This pharmacological profile would be advantageous in many clinical settings involving patients who require opioids for essential pain relief (e.g., those just having undergone surgery) and who cannot be administered opioid receptor antagonists to overcome serious ventilatory depression.

\section{Methods}

\section{Rats and surgical procedures}

All studies were carried out in accordance with the NIH Guide for the Care and Use of Laboratory Animals (NIH Publication No. 80-23) revised in 1996. The protocols were approved by the Animal Care and Use Committees of the University of Virginia and Case Western Reserve University. In addition, all studies were carried out in compliance with the ARRIVE (Animal Research: Reporting of In Vivo Experiments) guidelines (http://www.nc3rs.org.uk/page.asp?id=1357). Adult male Sprague-Dawley rats (Harlan, Madison, WI, USA) were implanted with jugular vein catheters under $2 \%$ isoflurane anesthesia and some rats received femoral arterial catheters. ${ }^{23}$ The rats were allowed at least four days to recover from surgery before use. All arterial catheters were flushed daily with heparin solution (50 units of heparin in phosphate-buffered saline at $0.1 \mathrm{M}, \mathrm{pH}$ 7.4). All catheters were flushed with phosphate-buffered saline (0.1 M, pH 7.4) approximately four hours before commencement of the experiments. All studies were performed in a quiet laboratory with relative humidity of $49 \pm 2 \%$ and room temperature of $21.4 \pm 0.2^{\circ} \mathrm{C}$.

\section{Whole-body plethysmography measurement of ventilatory parameters}


Ventilatory parameters were recorded in freely moving rats by whole body plethysmography (PLY3223; Data Sciences International, St. Paul, MN) as described previously. ${ }^{23-27}$ The rats were paced in individual chambers and given $60 \mathrm{~min}$ to acclimatize to allow true resting ventilatory parameters to be established. Study 1 - see Supplemental Table 1: Two groups of rats received a bolus injection of morphine (10 $\mathrm{mg} / \mathrm{kg}, \mathrm{IV}$ ) and after $15 \mathrm{~min}$, one group received an injection of vehicle (saline) whereas the other received an injection of D-cystine diEE ( $500 \mathrm{mmol} / \mathrm{kg}, \mathrm{IV}$ ) and ventilatory parameters were recorded for a further 75 min. Study 2 - see Supplemental Table 3: Two groups of rats received a bolus injection of morphine (10 $\mathrm{mg} / \mathrm{kg}, \mathrm{IV}$ ) and after $15 \mathrm{~min}$, one group received an injection of vehicle (saline) whereas the other received an injection of D-cystine $(500 \mathrm{mmol} / \mathrm{kg}$, IV) and ventilatory parameters were recorded for a further $75 \mathrm{~min}$. Study 3 - see Supplemental Table 4: Two groups of rats received a bolus injection of morphine (10 $\mathrm{mg} / \mathrm{kg}, \mathrm{IV}$ ) and after $15 \mathrm{~min}$, one group received an injection of vehicle (saline) whereas the other received an injection of L-NACme $(500 \mathrm{mmol} / \mathrm{kg}$, IV). The rats received another injection of vehicle or L-NACme $(500 \mathrm{mmol} / \mathrm{kg}$, IV) $15 \mathrm{~min}$ later and ventilatory parameters were recorded for a further $60 \mathrm{~min}$.

Due to the closeness of the body weights of all of the groups of rats, ventilatory data are shown without any corrections for body weight. The provided software (Fine Pointe, BUXCO) constantly corrected digitized values for changes in chamber temperature and humidity. Pressure changes associated with the respiratory waveforms were then converted to volumes (i.e., TV, PIF and PEF) using the algorithm of Epstein and colleagues. ${ }^{28,29}$ Specifically, factoring in chamber temperature and humidity, the cycle analyzers filtered the acquired signals, and BUXCO algorithms (Fine Pointe) generated an array of box flow data that identified a waveform segment as an acceptable breath. From that data vector, the minimum and maximum values were determined. Flows at this point were considered to be "box flow" signals. From this array, the minimum and maximum box flow values were determined and multiplied by

a compensation factor provided by the selected algorithm $(50,51)$ thus producing TV, PIF and PEF values that were used to determine accepted and rejected waveforms reported as Rejection Index (non-eupneic breathing. ${ }^{30}$

\section{Protocols for blood gas measurements and determination of Arterial-alveolar gradient}

The changes in $\mathrm{pH}, \mathrm{pCO}_{2}, \mathrm{pO}_{2}$ and $\mathrm{sO}_{2}$ elicited by injection of morphine $(10 \mathrm{mg} / \mathrm{kg}$, IV) in 3 separate groups of freely moving rats ( $\mathrm{n}=9$ rats per group) followed $15 \mathrm{~min}$ later by injection of vehicle (saline; 80.0 \pm 0.6 days of age; $342 \pm 2 \mathrm{~g}$ body weight), D-Cystine $(500 \mathrm{mmol} / \mathrm{kg}, \mathrm{IV} ; 79.7 \pm 0.4$ days; $340 \pm 2 \mathrm{~g})$ or Dcystine diME ( $500 \mathrm{mmol} / \mathrm{kg}$, IV; $79.3 \pm 0.4$ days; $338 \pm 2 \mathrm{~g}$ ) were determined as detailed previously (49). Arterial blood samples $(100 \mu \mathrm{L})$ were taken $15 \mathrm{~min}$ before and $15 \mathrm{~min}$ after injection of morphine (10 $\mathrm{mg} / \mathrm{kg}, \mathrm{IV})$. The rats then immediately received an injection of vehicle, D-cystine or D-cystine diME and blood samples were taken $5,15,30$ and 45 min later. The $\mathrm{pH}, \mathrm{pCO}_{2}, \mathrm{pO}_{2}$ and $\mathrm{sO}_{2}$ were measured using a Radiometer blood-gas analyzer (ABL800 FLEX). The A-a gradient measures difference between alveolar and arterial blood $\mathrm{O}_{2}$ concentrations. ${ }^{23,31,32} \mathrm{~A}$ decrease in $\mathrm{PaO}_{2}$, without a change in A-a gradient is normally accompanied by an increase in $\mathrm{paCO}_{2}$ (as observed here) if it is caused by hypoventilation. Hypoxia is irreversible if caused by shunt. An increased A-a gradient is caused either by oxygen diffusion 
limitation (usually not readily reversible) or ventilation-perfusion mismatch. ${ }^{23,31,32} \mathrm{~A}$-a gradient $=\mathrm{PAO}_{2}$ $\mathrm{PaO}_{2}$, where $\mathrm{PAO}_{2}$ is the partial pressure of alveolar $\mathrm{O}_{2}$ and $\mathrm{PaO}_{2}$ is $\mathrm{pO}_{2}$ in arterial blood. $\mathrm{PAO}_{2}=\left[\left(\mathrm{FiO}_{2} \mathrm{X}\right.\right.$ $\left(\mathrm{P}_{\mathrm{atm}}-\mathrm{P}_{\mathrm{H} 2 \mathrm{O}}\right)-\left(\mathrm{PaCO}_{2} /\right.$ respiratory quotient $\left.)\right]$, where $\mathrm{FiO}_{2}$ is the fraction of $\mathrm{O}_{2}$ in inspired air; $\mathrm{P}_{\text {atm }}$ is atmospheric pressure; $\mathrm{P}_{\mathrm{H} 2 \mathrm{O}}$ is the partial pressure of $\mathrm{H}_{2} \mathrm{O}$ in inspired air; $\mathrm{PaCO}_{2}$ is $\mathrm{pCO}_{2}$ in arterial blood; and respiratory quotient (RQ) is the ratio of $\mathrm{CO}_{2}$ eliminated/ $\mathrm{O}_{2}$ consumed. We took $\mathrm{FiO}$ of room-air to be $21 \%=0.21, \mathrm{P}_{\mathrm{atm}}$ to be $760 \mathrm{mmHg}$, and $\mathrm{P}_{\mathrm{H} 2 \mathrm{O}}$ to be $47 \mathrm{mmHg}^{23}$ We took the RQ value of our adult male rats to be $0.9 .{ }^{33,34}$ Here, we had both alveolar hypoventilation and ventilation-mismatch. In almost all cases, when these two phenomena occur together and are readily reversed, the cause is decreased minute ventilation leading rapidly to atelectasis.

\section{Antinociception protocols}

Tail-Flick latency (TFL): The antinociceptive effects of morphine, vehicle and D-cystine diEE were assessed by tail-flick latency (TFL) test using a Tail-Flick Analgesia Meter (IITC Life Science Inc., USA) as described previously. ${ }^{23,35-38}$ This involved minor manual restraint while positioning the tail to apply a thermal stimulus sufficient to induce a latency of tail withdrawal of about $3.0 \mathrm{sec}$ in all animals. Baseline TFL was tested in all rats (-20 min time-point in Figure 7). One group of rats (79.0 \pm 0.6 days of age; $338 \pm$ $2 \mathrm{~g}$ body weight, $\mathrm{n}=9$ rats) received an IV injection of vehicle (saline, $100 \mathrm{~mL} / 100 \mathrm{~g}$ body weight) and the second group ( $79.7 \pm 0.6$ days; $342 \pm 2 \mathrm{~g}, \mathrm{n}=9$ rats) received an injection of $D$-cystine diEE $(500 \mathrm{mmol} / \mathrm{kg}$, IV). TFL was tested in both groups 10 and $20 \mathrm{~min}$ later (-10 and 0 min in Figure 7). At 20 min postinjection (time 0 ), all rats received an injection of morphine (10 mg/ $\mathrm{kg}, \mathrm{IV}$ ) and TFL tested $20,40,60,90$, $120,150,180,210,240,360$ and 480 min post-injection. Data are shown as actual TFL (sec) and as "maximum possible effect" (\%MPE) using the formula, \%MPE = [(post-injection TFL - baseline TFL)/(12 - baseline TFL)] x 100.23,35-38

\section{Analgesia assessment by Paw withdrawal Assay}

Hot-Plate Latency (HPL): The antinociceptive effects of morphine, vehicle and D-cystine diEE were assessed by hot-plate (hindpaw withdrawal) latency (HPL) test using the Hargreaves's test. ${ }^{39}$ In brief, paw withdrawal latency to a thermal stimulus was assessed using a radiant heat source (IITC, CA, USA) aimed at the planter surface of the left hind-paw. This method did not involve restraint while positioning the thermal stimulus sufficient enough to induce a latency of tail withdrawal of $20 \mathrm{sec}$ (baseline values) prior to injection of any drug (cut-off latency of $20 \mathrm{sec}$ was set to avoid tissue damage). Baseline HPL was tested in all rats (-20 min time-point in Figure 7). One group of rats ( $80.3 \pm 0.6$ days of age; $340 \pm 3 \mathrm{~g}$ body weight, $n=9$ rats) received an IV injection of vehicle (saline, $100 \mathrm{~mL} / 100 \mathrm{~g}$ body weight) and the second group ( $80.0 \pm 0.5$ days; $339 \pm 3 \mathrm{~g}, \mathrm{n}=9$ rats) received an injection of D-cystine diEE $(500 \mathrm{mmol} / \mathrm{kg}, \mathrm{IV})$. $\mathrm{HPL}$ was tested in both groups 10 and 20 min later (-10 and 0 min in Figure 7). At 20 min post-injection (time 0$)$, all rats received an injection of morphine (10 mg/kg, IV) and HPL was tested 20, 40, 60, 90, 120, $150,180,210,240,360$ and 480 min post-injection. Data are shown as actual HPL (sec) and as 
"maximum possible effect" (\%MPE) using the formula, \%MPE = [(post-injection HPL - baseline HPL)/(20 - baseline HPL)] x 100.

\section{Statistics}

The recorded data (1 min bins) and derived parameters, $\mathrm{Vt} / \mathrm{Ti}$ and Response Area (cumulative percent changes from pre-values) were taken for statistical analyses. The pre-drug $1 \mathrm{~min}$ bins excluded occasional marked deviations from resting due to movements or scratching by the rats. These exclusions ensured accurate determinations of baseline parameters. The data are presented as mean \pm SEM. All data were analyzed by one-way or two-way analysis of variance followed by Student's modified $t$ test with Bonferroni corrections for multiple comparisons between means using the error mean square terms from each ANOVA. ${ }^{40,41}$ A value of $P<0.05$ denoted the initial level of statistical significance that was modified according to the number of comparisons between means as detailed by Wallenstein et al (1980). ${ }^{41}$

\section{Results}

\section{Ventilatory parameters}

The ages and body weights of the rats and their resting ventilatory parameters prior to the commencement of the whole-body plethysmography protocols are shown in Supplemental Table 1. There were no between-group differences for any parameter ( $P>0.05$, for all comparisons). A summary of the maximal initial responses elicited by morphine and the total effects recorded over the $15 \mathrm{~min}$ prior to the injection of D-cystine diEE are summarized in Supplemental Table 2. The changes in frequency of breathing (Freq), tidal volume (TV) and minute ventilation (MV) upon injection of morphine (10 mg/ $\mathrm{kg}$, IV) and subsequent injection of vehicle or D-cystine diEE $(500 \mu \mathrm{mol} / \mathrm{kg}$, IV) are summarized in Fig. 1 . The injection of morphine elicited a brief increase in Freq that was followed a relatively transient decrease that recovered before injection of vehicle of D-cystine diEE. Injection of vehicle did not elicit an immediate response in Freq, which remained at pre-injection values throughout the recording period. The injection of D-cystine diEE elicited a brief increase in Freq of about $5 \mathrm{~min}$ in duration that was followed by a gradual and sustained elevation in FrEq. The injection of morphine elicited a prompt and sustained decrease in TV that was still pronounced at the time that vehicle of D-cystine diEE was given. Injection of vehicle did not affect TV, which gradually recovered to pre-injection levels toward the end of the recording period. As a result of the above changes in Freq and TV, it can be seen that morphine elicited a transient increase in MV that was followed by a sustained decrease and that D-cystine diEE elicited a prompt and long-lasting reversal of this effect of morphine.

As summarized in Fig. 2, morphine elicited a transient decrease in Ti and Te that was followed by sustained increases in $\mathrm{Ti}$ and decreases in Te in rats that received vehicle $15 \mathrm{~min}$ after injection of morphine. The injection of D-cystine diEE elicited a brief decrease in Ti without greatly affecting Te. The long-lasting increase in Ti elicited by morphine was minimally smaller in D-cystine diEE-treated rats whereas the long-lasting decrease in Te was observably greater in the presence of D-cystine diEE. The 
ratio of $\mathrm{Te} / \mathrm{Ti}$ fell markedly after the administration of morphine in the vehicle treated rats and similarly in the D-cystine diEE-treated rats.

Figure 3 demonstrates that morphine elicited a pronounced and sustained decrease in PIF but lesser decreases in PEF in vehicle-treated rats. D-cystine diEE elicited a prompt and relatively sustained reversal of the effects of morphine on PIF and a marked increase in PEF to levels well above pre-morphine levels. Except for a decrease in PEF/PIF immediately upon injection of D-cystine diEE, the temporal changes in PEF/PIF elicited by morphine were similar in both groups.

Figure 4 demonstrates that morphine elicited a sustained increase in $\mathrm{EF}_{50}$ in rats that received vehicle. Administration of D-cystine diEE elicited a further prompt and sustained increase in $\mathrm{EF}_{50}$ in morphinetreated rats. Morphine elicited a prompt and sustained decrease in inspiratory drive (TV/Ti) and relatively pronounced but shorter-lived decrease in expiratory drive (TV/Te). The injection of D-cystine diEE elicited a noticeable but partial recovery of inspiratory drive and a substantial and sustained increase in expiratory drive to well above pre-morphine levels.

The initial peak responses and the total responses elicited by vehicle or D-Cystine diEE in morphinetreated rats are shown in Supplemental Fig. 1. D-Cystine diEE elicited pronounced increases in Freq (along with a decrease in Ti but not Te, and an increase in Te/Ti), TV, MV, PIF and PEF (with a decrease in $\mathrm{PE} / \mathrm{PEF}$ ), $\mathrm{EF}_{50}$, and inspiratory drive (TV/Ti and expiratory drive (TV/Te). In terms of the total response, Dcystine diEE elicited a relatively minor increase in Freq and decreases in $\mathrm{Ti}$ and $\mathrm{Te}$, but robust sustained increases in TV, MV, PIF, PEF, PEF/PIF, $\mathrm{EF}_{50}$ and in inspiratory drive and expiratory drives.

In contrast to D-cystine diEE, the injection of D-cystine $(500 \mu \mathrm{mol} / \mathrm{kg}$, IV) did not elicit immediate effects on Freq, TV or MV in morphine $(10 \mathrm{mg} / \mathrm{kg}$, IV)-treated rats although these parameters returned toward premorphine levels more quickly than in the vehicle-treated rats as seen in the last $15 \mathrm{~min}$ of the recording period (Supplemental Fig. 2, Supplemental Table 3). In addition, the injection of N-acetyl-L-cysteine methyl ester (L-NACme, $2 \times 500 \mu \mathrm{mol} / \mathrm{kg}$, IV), which is a highly cell penetrable reducing agent, ${ }^{21}$ elicited minor effects on morphine (10 mg/kg, IV)-induced changes in Freq, TV and MV (Supplemental Fig. 3,

\section{Supplemental Table 3).}

\section{Blood-Gas Chemistry}

The changes in $\mathrm{pH}, \mathrm{pCO}_{2}, \mathrm{pO}_{2}$ and $\mathrm{sO}_{2}$ elicited by injection of morphine $(10 \mathrm{mg} / \mathrm{kg}$, IV) in 3 separate groups of freely moving rats followed by injection of vehicle (VEH, saline), D-Cystine (500 $\mu \mathrm{mol} / \mathrm{kg}, \mathrm{IV}$ ) or D-cystine diME (500 $\mu \mathrm{mol} / \mathrm{kg}, \mathrm{IV})$ are summarized in Fig. 5 . The M15-M60 term on each $\mathrm{x}$-axis refers to 15-60 min after injection of morphine whereas D5-D45 refers to 5-45 min after injection of drug (vehicle, D-Cystine or D-cystine diME). Morphine elicited substantial falls in $\mathrm{pH}, \mathrm{pO}_{2}$ and $\mathrm{sO}_{2}$ accompanied by substantial increases in $\mathrm{pCO}_{2}$ (see time M15) Pre-values and responses to morphine were similar in the 3 groups. These values returned toward pre-injection after injection of vehicle. The values returned toward pre-injection levels faster after injection of D-cystine with these changes reaching significance at M45:D30 and M60:D45 time-points. The morphine-induced changes in ABG chemistry were reversed 
immediately (at M20:D5) by injection of D-cystine diME and this reversal was sustained throughout the experiment (at M60:D45). In contrast, the injection of D-cystine diME (500 $\mu \mathrm{mol} / \mathrm{kg}$, IV) elicited minimal immediate effects on Freq, TV and MV in morphine (10 mg/kg, IV)-treated rats

\section{Alveolar-arterial gradients}

The changes in A-a gradients in the 3 groups of freely moving rats described under Blood-gas Chemistry elicited by morphine (10 mg/kg, IV) and then vehicle (VEH, saline), D-Cystine (500 $\mu \mathrm{mol} / \mathrm{kg}, \mathrm{IV})$ or Dcystine diME $(500 \mu \mathrm{mol} / \mathrm{kg}$, IV) are shown in Fig. 6. Morphine elicited substantial and equivalent increases in $\mathrm{pCO}_{2}$ in the 3 groups of rats (see time M15). These values did not return to pre-injection levels after injection of vehicle but returned toward pre-injection levels after injection of D-cystine, with these changes being significant at M45:D30 and M60:D45 times. Morphine-induced increases in A-a gradient were reversed immediately (at M20:D5) by D-cystine diME and this reversal was sustained throughout the experiment (at M60:D45).

\section{Antinociception assays}

We first tested the effects of D-cystine diME $(500 \mu \mathrm{mol} / \mathrm{kg}$, IV) or L-cystine diME ( $500 \mu \mathrm{mol} / \mathrm{kg}$, IV) on analgesic status of adult male rats when given alone or when given in combination with morphine sulfate $(1.0 \mathrm{mg} / \mathrm{kg}$, IV) with testing performed between 20 to 30 min post-injection (see Supplement section, Effects of D-cystine diME and L-cystine diME on Analgesia Status, including Supplementary Figs. 4-7 and accompanying text and references). In brief, neither D-cystine diME nor L-cystine diME affected thermal hyperalgesia (Hargreaves Testing - heat applied to a hindpaw) or mechanical allodynia (Von Frey Testing - pressure applied to a hindpaw) when given alone and neither thiolester affected the analgesic actions of morphine. However, we wanted to further explore whether D-cystine diME would affect a higher dose of morphine and to track the changes in analgesic status over a much longer timecourse. Changes in tail-flick latencies (TFL, top panel) and hot-plate latencies (HPL, bottom panel) elicited by injection of vehicle or D-cystine diEE ( $500 \mu \mathrm{mol} / \mathrm{kg}$, IV) and subsequent injection of morphine (10 $\mathrm{mg} / \mathrm{kg}, \mathrm{IV}$ ) in freely moving male rats are summarized in Fig. 7. D-cystine diEE elicited a transient increase in TFL and HPL (both effects indicative of antinociception) that resolved within 15 min (time 0). The injection morphine elicited a pronounced increase in TFL and HPL of at least $4 \mathrm{~h}$ in duration in vehicle-treated rats. The antinociceptive effects of morphine were enhanced in D-cystine diEE-treated rats in that the maximal possible effect (\%MPE) and duration of antinociception was greater than in vehicletreated rats from 90 min after morphine injection. The antinociceptive effects of morphine were also enhanced by D-cystine ( $500 \mu \mathrm{mol} / \mathrm{kg}$, IV) although to a lesser degree than by D-cystine diEE (Supplemental Table 5).

\section{Sedation}

All rats that received morphine $(10 \mathrm{mg} / \mathrm{kg}$, IV) plus vehicle remained obviously sedated (they remained on their side not moving with their eyes closed) for at approximately 60 min, after which time they gradually recovered their footing and were able to groom and move about the chamber although full mobility was not evident for at least $2 \mathrm{~h}$. Sedation in the rats that received morphine plus $\mathrm{D}$-cystine diEE or D-cystine 
diME was indistinguishable from the rats the received morphine plus vehicle. The durations of the sedative and analgesic actions of morphine far exceeded the ventilatory depression elicited by the opioid (see Figs. 1-7).

\section{Discussion}

The present study demonstrates that the systemic injection of D-cystine diEE or D-cystine diME elicit an immediate and sustained reversal of the negative effects of a $10 \mathrm{mg} / \mathrm{kg}$ dose of morphine on ventilatory parameters, gas exchange in the lungs (elevated A-a gradient) and $A B G$ chemistry in unanesthetized adult male Sprague-Dawley rats without (apparently) affecting the sedative effects of morphine and while augmenting the antinociceptive effects of the opioid. Taken together, it would appear unlikely that Dcystine diEE or D-cystine diME directly modulate the pharmacological actions of morphine by competitive or non-competitive blockade of opioid receptors since all of the above effects of morphine are antagonized by opioid receptor antagonists such as naloxone and naltrexone. ${ }^{1-5}$ The site(s) of action and molecular mechanisms by which D-cystine diEE or D-cystine diME exert their robust effects on ventilatory parameters, A-a gradient and ABG chemistry in morphine-treated rats while augmenting the antinociceptive effects of the opioid, remain to be determined. Evidence that morphine blocks the entry of L-cysteine into neurons via inhibition of EAA3 ${ }^{6,7}$ raises the possibility that either (a) a decrease in intracellular levels of L-cysteine and resulting enhancement of the oxidative (less reductive) status of the cell $^{6,7}$ and/or (b) loss of participation of L-cysteine in a myriad of intracellular metabolic pathways including the generation of the gaseous neurotransmitter hydrogen sulfide, ${ }^{42-44}$ plays a role in the deleterious actions of morphine while conversely promoting the antinociceptive and sedative actions of the opioid.

The potent actions of D-cystine diEE, D-cystine diME and L-cysteine ethyl ester ${ }^{22}$ on the negative effects of morphine on ventilation and gas-exchange support these concepts whereas the ability of the thiolesters to augment the antinociceptive actions of morphine does not. Transport of cystine esters into the cell would not itself correct for the loss of sulfhydryl equivalents since cystine is already in the more oxidized disulfide state, and D-cystine or D-cysteine would not participate in most of the metabolic pathways of L-cysteine, but uptake of D-cystine esters could potentially drive up levels of intracellular Lcysteine. However, our finding that the highly cell-permeable thiolester reducing agent, $\mathrm{N}$-acetyl-L-cysteine methyl ester, ${ }^{21}$ had minimal effects on the ventilatory depressant effects of morphine suggests that $D$ cystine diEE and D-cystine diME do not act simply by increasing reducing equivalents in cells. Potential mechanisms of action of D-cystine diEE and D-cystine diME may involve (a) interference with opioid receptor-linked $\beta$-arrestin cell signaling, which would spare the Gprotein-mediated antinociceptive actions of morphine, ${ }^{45,46}$ and/or conversion of these thiolesters to bioactive S-nitrosothiols (i.e., S-nitroso-Dcystine diEE, S-nitroso-D-cystine diME) that may act as intracellular nitrosating agents similar to Snitroso-L-cysteine ethyl ester $(28,29) .{ }^{47,48}$ S-nitrosothiols in the brainstem, peripheral structures and red blood cells play important roles in ventilatory control processes. ${ }^{49-53}$ For example, microinjection of Snitrosothiols into the nucleus tractus solitarius elicit robust increases in $\mathrm{MV}^{52}$ as do systemic delivery of 
S-nitrosothiols to the carotid bodies. ${ }^{53}$ Our evidence that S-nitrosothiols such as S-nitroso-L-cysteine exert their ventilatory effects via direct modulation of voltage-gated $\mathrm{K}^{+}$-channels may represent a molecular target for D-cystine diEE and D-cystine diME and their S-nitrosothiol forms, which may target the intracellular domains of these channels.

As we reported previously, ${ }^{54-57}$ the $10 \mathrm{mg} / \mathrm{kg}$ dose of morphine elicited only a transient decrease in FrEq. This apparent lack of sustained effects on Freq is misleading in the sense that morphine elicited a profound and sustained increase in Ti and a sustained decrease in Te (present study). ${ }^{54-57}$ Despite evidence that the depressant effects of morphine on Freq involve suppression of carotid body chemoreceptor reflexes, ${ }^{57}$ we reported that the ventilatory depressant effects of morphine $(10 \mathrm{mg} / \mathrm{kg}, \mathrm{IV})$ in freely moving rats were exacerbated in rats with bilateral carotid sinus nerve transection, ${ }^{57}$ suggesting that morphine does not directly affect or potentially promotes carotid body chemoreflexes in these unanesthetized rats. D-cystine diEE had minor effects on the actions of morphine on the above parameters (i.e., Freq rose to higher levels than in vehicle-treated rats, whereas Ti did not rise as much and Te deceased to a greater extent). It would seem that the carotid body may not be a major site of direct action considering the minimal effects of the thiolester on Freq.

The first novel set of findings in the present study was that D-cystine diEE elicited an immediate and sustained reversal of the negative effects of morphine on TV (and therefore MV), PIF, PEF, and inspiratory and expiratory drives, while promoting the enhancing the effects of morphine on $\mathrm{EF}_{50}$. In contrast, the injection of the parent thiol, D-cystine, did not elicit immediate responses in morphine-treated rats, although Freq, TV and MV (and other variables, data not shown) returned to pre-morphine levels somewhat more rapidly than in vehicle-injected rats. The second novel set of findings was that D-cystine diME elicited an immediate and sustained reversal of the negative effects of morphine on ABG chemistry whereas D-cystine produced a gradual recovery that was greater than in vehicle-injected rats. This is related to the third novel finding that D-cystine diME elicited a prompt and sustained reversal of the negative effects of morphine on gas-exchange within the lungs (as defined by reversal of the morphineinduced increase in A-a gradient) whereas again, D-cystine promoted the recovery of the effects of morphine from about $30 \mathrm{~min}$ after the injection of the thiolester ( $45 \mathrm{~min}$ post-morphine). Taken together, the ability of D-cystine diEE/diME to reverse the above negative effects of morphine is due to a unique profile of activity that also includes potentiation of the antinociceptive actions of the opioid. With respect to antinociception, the ability of systemically injected D-cystine diEE to elicit a transient analgesia (as detected by both TF and HP assays) is consistent to a degree with evidence that direct injection of Dcystine into the hindpaw of rats elicited profound blockade of thermal nociception. ${ }^{58} \mathrm{D}$-cystine may exert its effects on nociceptive processing via redox modulation (closure) of ion-channels such as T-type voltage-gated $\mathrm{Ca}^{2+}$ channels. ${ }^{59}$ Moreover, Lee et $\mathrm{al}^{60}$ demonstrated that extracellular application of Snitrosothiols such as $\mathrm{S}$-nitrosoglutathione rapidly reduced $\mathrm{T}$-type $\mathrm{Ca}^{2+}$ current amplitudes in sensory cell bodies within dorsal root ganglia. Whether any of these actions participate in D-cystine diEE-induced promotion of the antinociceptive effects of morphine remains to be determined. Obviously numerous processes such as alterations in opioid receptor status (e.g., desensitization, phosphorylation, 
internalization) and promotion of the intracellular cascades by which opioids induce antinociception may be involved. ${ }^{61,62}$

The gradual appearance of effects of D-cystine on morphine-induced changes in ventilatory parameters, ABG chemistry, A-gradient and TFL raises the possibility that D-cystine diEE and D-cystine diME exert their effects via rapid introduction of D-cystine into cells as opposed to gradual entry of D-cystine through uptake systems. The uptake of L-cystine into cells is mediated by the cystine-glutamate antiporter system $\mathrm{x}^{\mathrm{c}-}$ and the $\mathrm{Na}^{+}$-independent high-affinity cystine transporter, b0,+AT. ${ }^{63-65}$ There is evidence that cystineglutamate antiporter system $\mathrm{x}^{\mathrm{c}^{-}}$does not transport $\mathrm{D}$-cystine ${ }^{64}$ and to our knowledge it is not known whether D-cystine is transported by b0,+AT. As such, the mechanisms (e.g., facilitated entry via transporters, conversion to other compounds which gain cell entry or act on membrane proteins), by which D-cystine exerts its latent effects remain unknown, but are worthy of examination.

\section{Conclusion}

We present evidence here that D-cystine diEE, D-cystine diME and to a lesser degree, D-cystine itself, represent a novel class of compounds that have an important therapeutic profile that may be of value in the clinic to treat opioid-induced respiratory depression without compromising analgesia. We have established methods to determine the pharmacokinetic profile of D-cystine diME in dog plasma ${ }^{66}$ and developed an ultra-sensitive method to detect trace concentrations of S-nitrosothiols by means of a capacitive sensor. ${ }^{67}$ It will be of considerable interest to see whether the pharmacokinetics of D-cystine diEE and D-cystine diME are altered meaningfully by opioids and whether the thiolesters indeed generate and/or are converted to S-nitrosothiols.

\section{Declarations}

\section{Acknowledgments}

We acknowledge Chelsea Csuhran for her superb administrative assistance, Tristan H.J. Lewis for editorial assistance and Amia Andrade for her work on the behavioral testing at LLU.

Abbreviated Title (Running Head): D-cystine di(m)ee attenuates opioid respiratory depression

Summary Statement (35 words): Morphine-induced respiratory depression but not analgesia in rats is reversed by systemic injection of D-Cystine di $(m)$ ethyl ester. These and other thiolesters may represent a novel series of agents to combat the negative effects of opioids.

\section{Funding and Disclosure}

This work was supported by NIH grants 1P01HL101871 (to BG, JNB and SJL), 1 P01HL128192 (to BG), 1R61HL154136-01 (to BG and SJ), and U01DA051373 (to SJL), and grants from the Harrington Discovery Institute (to BG); the Children's Lung Foundation (to BG); an Eli Lilly Foundation INCITE Grant (to BG); and 
the Riley Children's Foundation (to BG). BG is a founder and equity owner in Lake Effect Pharma, LLC. Additional support from Case Western Reserve University (Harrington Discovery Institute grant to BG) was provided to CGW via an intra-mural Collaborative Research Grant through the Department of Pediatrics, Loma Linda University.

\section{Conflict of interest statement}

The authors have declared that no conflicts of interest exist.

\section{Author contributions}

BG, SMB, JNB, AG, CGW and SJL designed the research experiments. WJM, APY, JNB, CGW and SJL performed the experiments. BG, AG, JNB, JMS, CWG and SJL analyzed data. BG, CGW, JNB and SJL prepared the manuscript. BG, SMB, WJM, APY, AG, JNB, JMS, CGW and SJL edited the manuscript and approved it for submission.

\section{References}

1. Algera, M. H. et al. Opioid-induced respiratory depression in humans: a review of pharmacokineticpharmacodynamic modelling of reversal. Brit. J. Anaesth. 122, e168-e179 (2019).

2. Boom, M. et al. Non-analgesic effects of opioids: opioid-induced respiratory depression. Curr. Pharm. Des. 18, 5994-6004 (2012).

3. van Dorp, E., Yassen, A. \& Dahan, A. Naloxone treatment in opioid addiction: the risks and benefits. Expert Opin. Drug Saf. 6, 125-132 (2007).

4. Dahan, A., Aarts, L., Smith, T. W. \& Incidence Reversal, and Prevention of Opioid-induced Respiratory Depression. Anesthesiology. 112, 226-238 (2010).

5. Dahan, A. et al. Averting Opioid-induced Respiratory Depression without Affecting Analgesia. Anesthesiology. 128, 1027-1037 (2018).

6. Trivedi, M., Shah, J., Hodgson, N., Byun, H. M. \& Deth, R. Morphine induces redox-based changes in global DNA methylation and retrotransposon transcription by inhibition of excitatory amino acid transporter type 3-mediated cysteine uptake. Mol. Pharmacol. 85, 747-757 (2014).

7. Trivedi, M. S. \& Deth, R. Redox-based epigenetic status in drug addiction: a potential contributor to gene priming and a mechanistic rationale for metabolic intervention. Front. Neurosci. 8, 444 (2015).

8. Rech, V. C. et al. Cysteamine prevents inhibition of thiol-containing enzymes caused by cystine or cystine dimethylester loading in rat brain cortex. Metab. Brain Dis. 23, 133-145 (2008).

9. Figueiredo, V. C., Feksa, L. R. \& Wannmacher, C. M. Cysteamine prevents inhibition of adenylate kinase caused by cystine in rat brain cortex. Metab. Brain Dis. 24, 723-731 (2009).

10. Gurbuz, N. et al. Cystine Dimethyl Ester Induces Apoptosis Through The Regulation of PKC- $\delta$ and PKC- $\varepsilon$ in Prostate Cancer Cells. Anticancer Agents Med. Chem. 15, 217-227 (2015). 
11. Chu, F., Chen, L. H. \& O'Brian, C. A. Cellular protein kinase $C$ isozyme regulation by exogenously delivered physiological disulfides - implications of oxidative protein kinase $\mathrm{C}$ regulation to cancer prevention. Carcinogenesis. 25, 585-596 (2004).

12. Lailey, A. F., Hill, L., Lawston, I. W., Stanton, D. \& Upshall, D. G. Protection by cysteine esters against chemically induced pulmonary oedema. Biochem. Pharmacol. 42 (Suppl), S47-S54 (1991).

13. Sumayao, R., McEvoy, B., Martin-Martin, N., McMorrow, T. \& Newsholme, P. Cystine dimethylester loading promotes oxidative stress and a reduction in ATP independent of lysosomal cystine accumulation in a human proximal tubular epithelial cell line. Exp. Physiol. 98, 1505-15017 (2013).

14. Lailey, A. F. \& Upshall, D. G. Thiol levels in rat bronchio-alveolar lavage fluid after administration of cysteine esters. Hum. Exp. Toxicol. 13, 776-780 (1994).

15. Ben-Nun, A., Bashan, N., Potashnik, R., Cohen-Luria, R. \& Moran, A. Cystine dimethyl ester reduces the forces driving sodium-dependent transport in LLC-PK1 cells. Am. J. Physiol. 263, C516-C520 (1992).

16. Foreman, J. W. \& Benson, L. Effect of cystine loading and cystine dimethylester on renal brush border membrane transport. Biosci. Rep. 10, 455-459 (1990).

17. Ito, L. et al. Glutathione ethylester, a novel protein refolding reagent, enhances both the efficiency of refolding and correct disulfide formation. Protein J. 31, 499-503 (2012).

18. Hobbs, M. J., Butterworth, M., Cohen, G. M. \& Upshall, D. G. Structure-activity relationships of cysteine esters and their effects on thiol levels in rat lung in vitro. Biochem. Pharmacol. 45, 1605-1612 (1993).

19. Servin, A. L., Goulinet, S. \& Renault, H. Pharmacokinetics of cysteine ethyl ester in rat. Xenobiotica. 18, 839-847 (1988).

20. Henderson, M. et al. Neuroproteomic study of nitrated proteins in moderate traumatic brain injured rats treated with gamma glutamyl cysteine ethyl ester administration post injury: Insight into the role of glutathione elevation in nitrosative stress. Proteomics Clin. Appl. 10, 1218-1224 (2016).

21. Tsikas, D. et al. S-Nitroso-N-acetyl-L-cysteine ethyl ester (SNACET) and N-acetyl-L-cysteine ethyl ester (NACET)-Cysteine-based drug candidates with unique pharmacological profiles for oral use as NO, H2S and GSH suppliers and as antioxidants: Results and overview. J. Pharm. Anal. 8, 1-9 (2018).

22. Mendoza, J. et al. L-Cysteine ethyl ester reverses the deleterious effects of morphine on, arterial blood-gas chemistry in tracheotomized rats. Respir Physiol Neurobiol. 189, 136-143 (2013).

23. Henderson, F. et al. Role of central and peripheral opiate receptors in the effects of fentanyl on analgesia, ventilation and arterial blood-gas chemistry in conscious rats. Respir. Physiol. Neurobiol. 191, 95-105 (2014). )

24. Young, A. P. et al. Co-activation of $\mu$ - and $\delta$-opioid receptors elicits tolerance to morphine-induced ventilatory depression via generation of peroxynitrite. Resp. Physiol. Neurobiol. 186, 255-264 (2013). )

25. May, W. J. et al. Morphine has latent deleterious effects on the ventilatory responses to a hypoxichypercapnic challenge. Open J. Mol. Integr. Physiol. 3, 134-145 (2013). ) 
26. May, W. J. et al. Morphine has latent deleterious effects on the ventilatory responses to a hypoxic challenge. Open J. Mol. Integr. Physiol. 3, 166-180 (2013). )

27. Baby, S. M. et al. Bilateral carotid sinus nerve transection exacerbates morphine-induced respiratory depression. Eur. J. Pharmacol. 834, 17-29 (2018). )

28. Epstein, M. A. \& Epstein, R. A. A theoretical analysis of the barometric method for measurement of tidal volume. Respir. Physiol. 32, 105-120 (1978).

29. Epstein, R. A., Epstein, M. A., Haddad, G. G. \& Mellins, R. B. Practical implementation of the barometric method for measurement of tidal volume. J. Appl. Physiol. 49, 1107-1115 (1980).

30. Getsy, P. M. et al. Enhanced non-eupneic breathing following hypoxic, hypercapnic or hypoxichypercapnic gas challenges in conscious mice. Respir. Physiol. Neurobiol. 204, 147-159 (2014).

31. Stein, P. D., Goldhaber, S. Z. \& Henry, J. W. Alveolar-arterial oxygen gradient in the assessment of acute pulmonary embolism. Chest. 107, 139-143 (1995).

32. Story, D. A. Alveolar oxygen partial pressure, alveolar carbon dioxide partial pressure, and the alveolar gas equation. Anesthesiology. 84, 1011 (1996).

33. Stengel, A. et al. Central injection of the stable somatostatin analog ODT8-SST induces a somatostatin2 receptor-mediated orexigenic effect: role of neuropeptide $Y$ and opioid signaling pathways in rats. Endocrinology. 151, 4224-4235 (2010).

34. Chapman, C. D. et al. Paraventricular nucleus anandamide signaling alters eating and substrate oxidation. Neuroreport. 23, 425-429 (2012).

35. Lewis, S. J., Meller, S. T., Brody, M. J. \& Gebhart, G. F. Reduced nociceptive effects of i.v. 5-HT in the SHR. Clin. Exp. Hypertens A. 13, 849-857 (1991).

36. Meller, S. T., Lewis, S. J., Brody, M. J. \& Gebhart, G. F. The peripheral nociceptive actions of intravenously administered 5-HT in the rat requires dual activation of both 5-HT2 and 5-HT3 receptor subtypes. Brain Res. 561, 61-68 (1991).

37. Carstens, E. \& Wilson, C. Rat tail flick reflex: magnitude measurement of stimulus-response function, suppression by morphine and habituation. J. Neurophysiol. 70, 630-639 (1993).

38. Golder, F. J. et al. Identification and Characterization of GAL-021 as a Novel Breathing Control Modulator. Anesthesiology. 123, 1093-1104 (2015).

39. Hargreaves, K., Dubner, R., Brown, F., Flores, C. \& Joris, J. A new and sensitive method for measuring thermal nociception in cutaneous hyperalgesia. Pain. 32, 77-88 (1988).

40. Winer, B. J. Statistical Principles of Experimental Designpp 752-809(McGraw-Hill Book Co, New York, NY, 1971).

41. Wallenstein, S., Zucker, C. L. \& Fleiss, J. L. Some statistical methods useful in circulation research. Circ. Res. 47, 1-9 (1980).

42. Paul, B. D., Sbodio, J. I. \& Snyder, S. H. Cysteine Metabolism in Neuronal Redox Homeostasis. Trends Pharmacol. Sci. 39, 513-524 (2018). 
43. Yin, J. et al. L-Cysteine metabolism and its nutritional implications. Mol. Nutr. Food Res. 60, 134-146 (2016).

44. Wu, G. Amino acids: metabolism, functions, and nutrition. Amino Acids. 37, 1-17 (2009).

45. Schmid, C. L. et al. Bias Factor and Therapeutic Window Correlate to Predict Safer Opioid Analgesics. Cell. 171, 1165-117513 (2017).

46. Grim, T. W., Acevedo-Canabal, A. \& Bohn, L. M. Toward Directing Opioid Receptor Signaling to Refine Opioid Therapeutics. Biol. Psychiatry. 87, 15-21 (2020).

47. Clancy, R., Cederbaum, A. I. \& Stoyanovsky, D. A. Preparation and properties of S-nitroso-L-cysteine ethyl ester, an intracellular nitrosating agent. J. Med. Chem. 44, 2035-2038 (2001).

48. Perissinotti, L. L., Turjanski, A. G., Estrin, D. A. \& Doctorovich, F. Transnitrosation of nitrosothiols: characterization of an elusive intermediate. J. Am. Chem. Soc. 127, 486-487 (2005).

49. Palmer, L. A. et al. Ventilatory responses during and following exposure to a hypoxic challenge in conscious mice deficient or null in S-nitrosoglutathione reductase. Resp. Physiol. Neurobiol. 185, 571-581 (2013).

50. Palmer, L. A. et al. Hypoxia-induced changes in protein S-nitrosylation in female mouse brainstem. Am. J. Respir. Cell. Mol. Biol. 52, 37-45 (2015).

51. Gaston, B. et al. Essential role of hemoglobin beta-93-cysteine in post-hypoxia facilitation of breathing in conscious mice. J. Appl. Physiol. 116, 1290-1299 (2014). )

52. Lipton, A. J. et al. S-nitrosothiols signal the ventilatory response to hypoxia. Nature. 413, 171-174 (2001).

53. Gaston, B. et al. Voltage-gated potassium channel proteins and stereoselective S-nitroso-I-cysteine signaling. JCl Insight. 5, e134174 (2020).

54. Young, A. P. et al. Co-activation of $\mu$-and $\delta$-opioid receptors elicits tolerance to morphine-induced ventilatory depression via generation of peroxynitrite. Resp. Physiol. Neurobiol. 186, 255-264 (2013). )

55. May, W. J. et al. Morphine has latent deleterious effects on the ventilatory responses to a hypoxichypercapnic challenge. Open J. Mol. Integr. Physiol. 3, 134-145 (2013). )

56. May, W. J. et al. Morphine has latent deleterious effects on the ventilatory responses to a hypoxic challenge. Open J. Mol. Integr. Physiol. 3, 166-180 (2013). )

57. Baby, S. M. et al. Bilateral carotid sinus nerve transection exacerbates morphine-induced respiratory depression. Eur. J. Pharmacol. 834, 17-29 (2018). )

58. Pathirathna, S., Covey, D. F. \& Todorovic, S. M. \& Jevtovic-Todorovic, V. Differential effects of endogenous cysteine analogs on peripheral thermal nociception in intact rats. Pain. 125, 53-64 (2006).

59. Todorovic, S. M. \& Jevtovic-Todorovic, V. Redox regulation of neuronal voltage-gated calcium channels. Antioxid. Redox Signal. 21, 880-891 (2014). 
60. Lee, J., Nelson, M. T., Rose, K. E. \& Todorovic, S. M. Redox mechanism of S-nitrosothiol modulation of neuronal CaV3.2 T-type calcium channels. Mol. Neurobiol. 48, 274-280 (2013).

61. Williams, J. T. et al. Regulation of $\mu$-opioid receptors: desensitization, phosphorylation, internalization, and tolerance. Pharmacol. Rev. 65, 223-254 (2013).

62. Connor, M. \& Christie, M. D. Opioid receptor signalling mechanisms. Clin. Exp. Pharmacol. Physiol. 26, 493-499 (1999).

63. Lewerenz, J. et al. The cystine/glutamate antiporter system $x(c)(-)$ in health and disease: from molecular mechanisms to novel therapeutic opportunities. Antioxid. Redox Signal. 18, 522-555 (2013).

64. Bannai, S. \& Kitamura, E. Transport of interaction of L-cystine and L-glutamate in human diploid fibroblasts in culture. J. Biol. Chem. 255, 2372-2376 (1980).

65. 46.Wagner, C. A., Lang, F. \& Bröer, S. Function and structure of heterodimeric amino acid transporters. Am. J. Physiol. Cell Physiol. 281, C1077-C1093 (2001).

66. Altawallbeh, G. et al. Pharmacokinetic study of Sudaxine in dog plasma using novel LC-MS/MS method. Drug Test. Anal. 11, 403-410 (2019).

67. Seckler, J. M. et al. Detection of trace concentrations of S-nitrosothiols by means of a capacitive sensor. PLoS One. 12, e0187149 (2017).

\section{Figures}


Figure 1
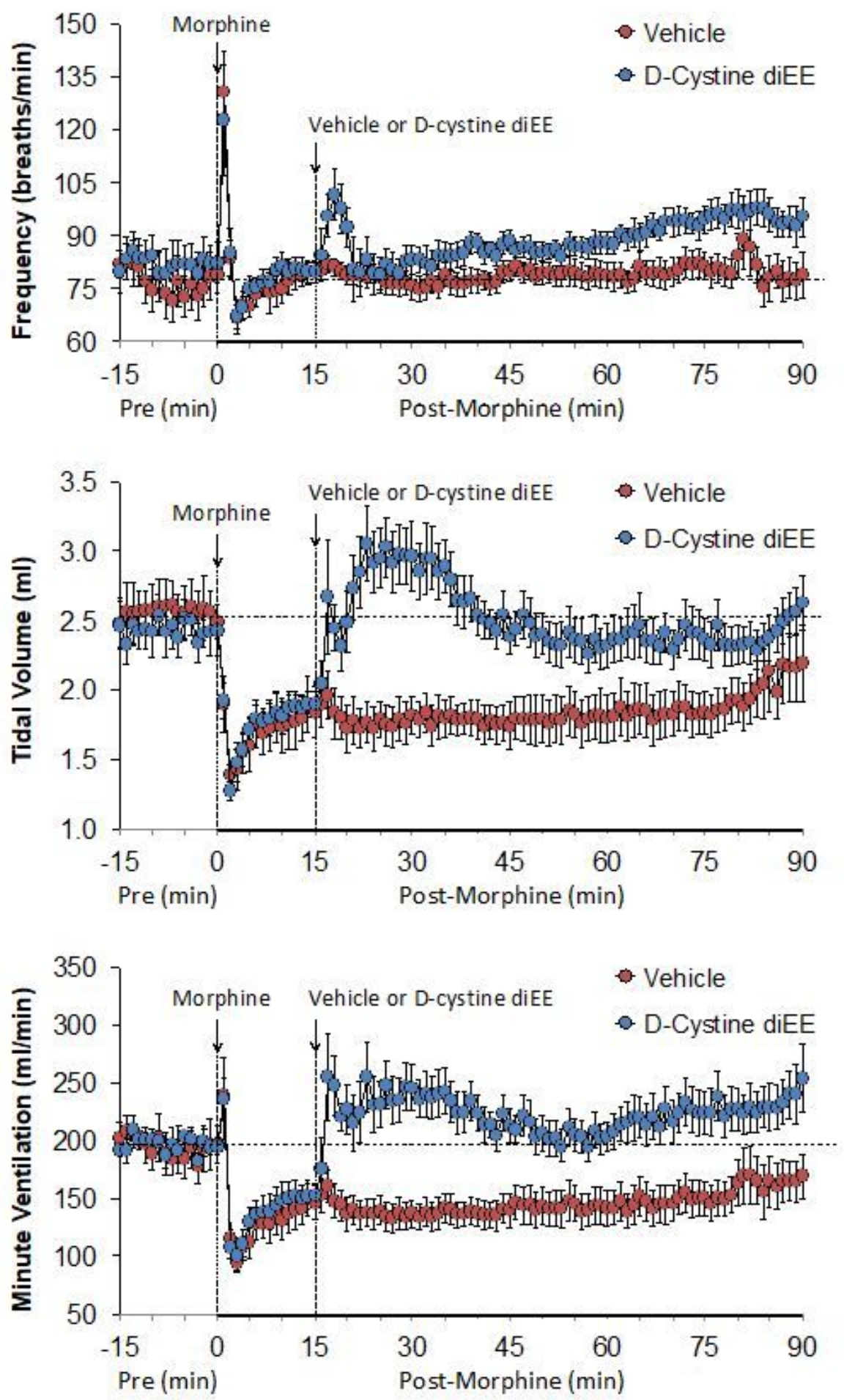

Figure 1

"See the Supplemental Files section for the complete figure caption". 


\section{Figure 2}
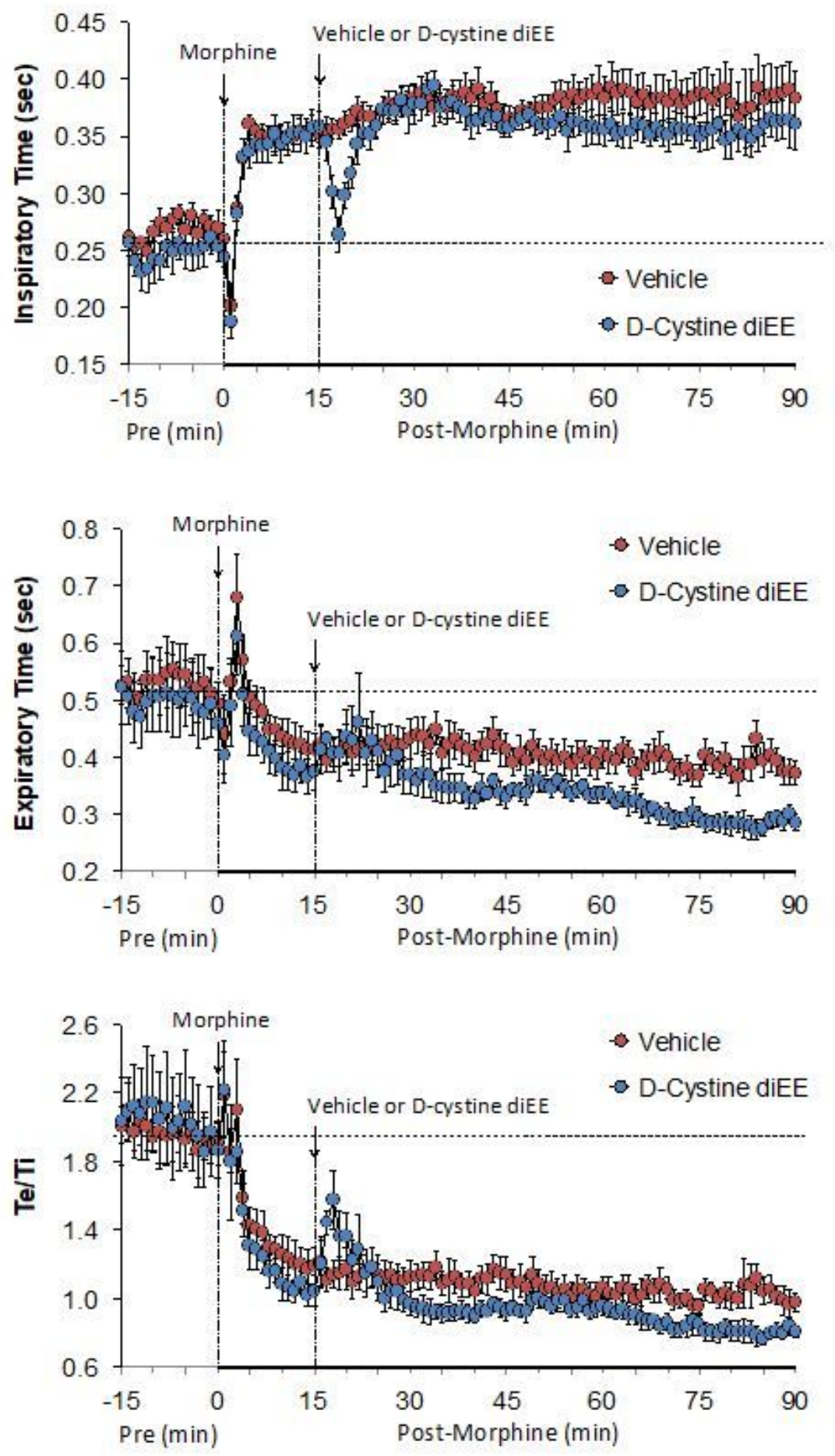

\section{Figure 2}

"See the Supplemental Files section for the complete figure caption". 


\section{Figure 3}
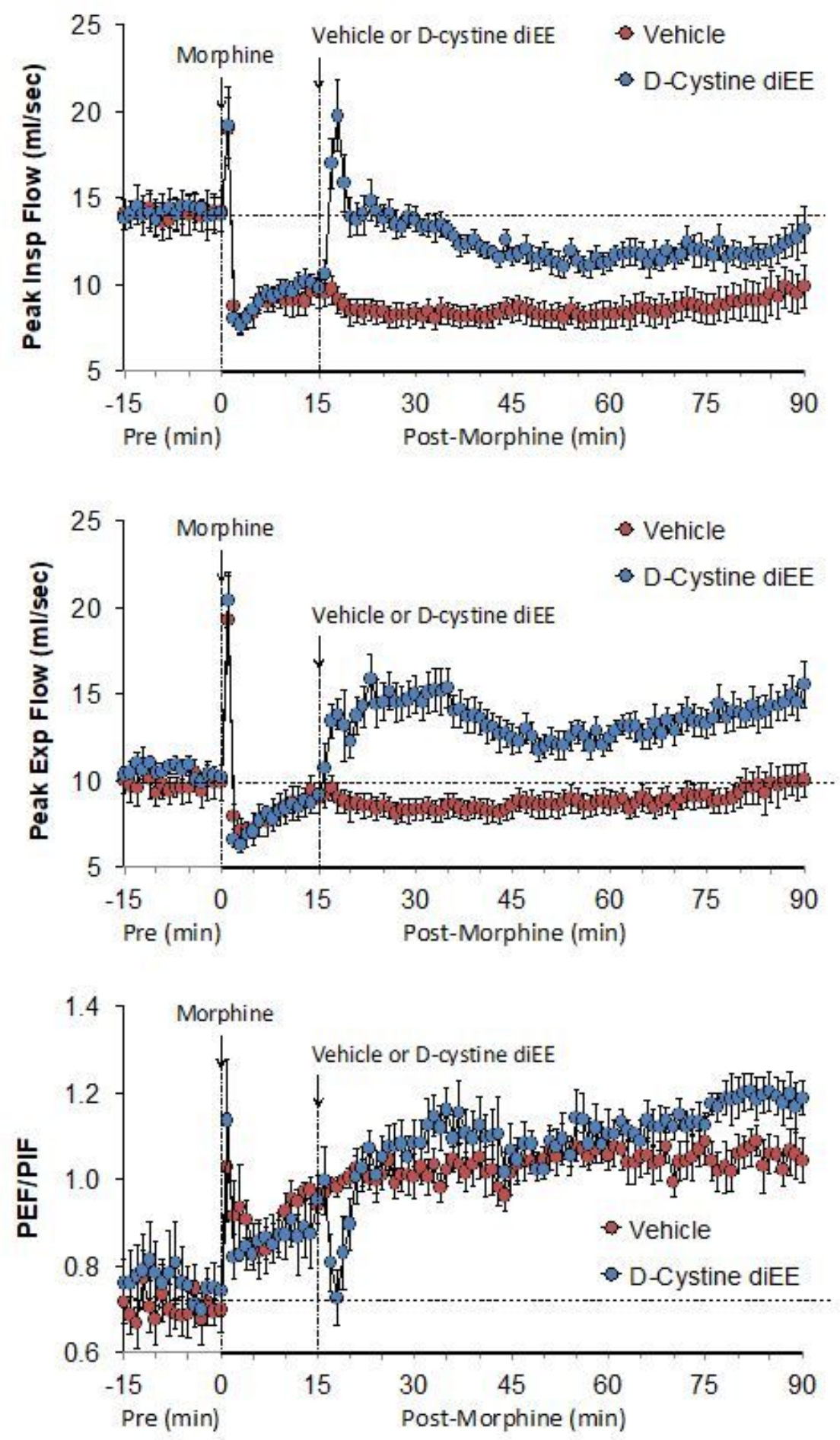

\section{Figure 3}

"See the Supplemental Files section for the complete figure caption". 


\section{Figure 4}
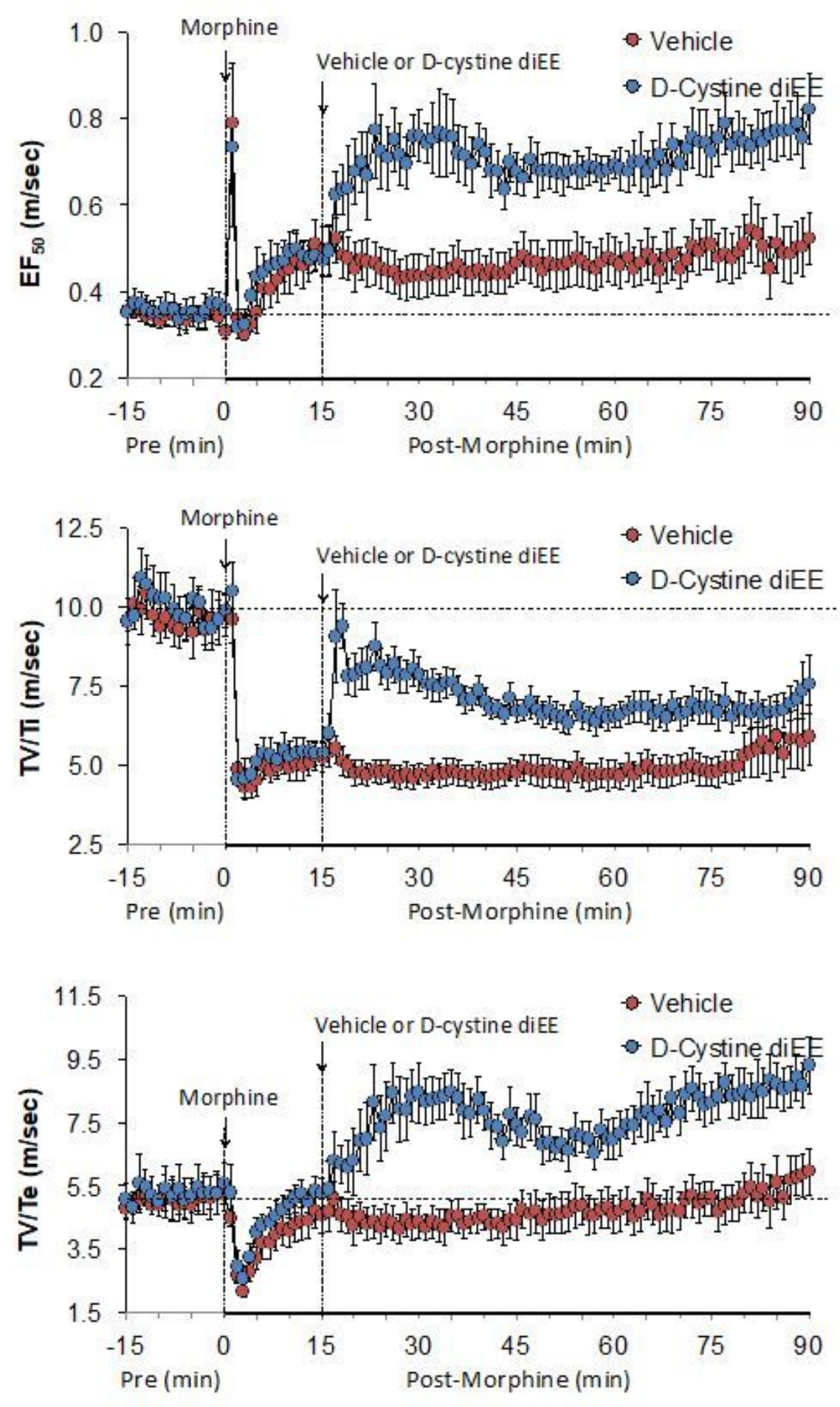

\section{Figure 4}

"See the Supplemental Files section for the complete figure caption". 
Figure 5
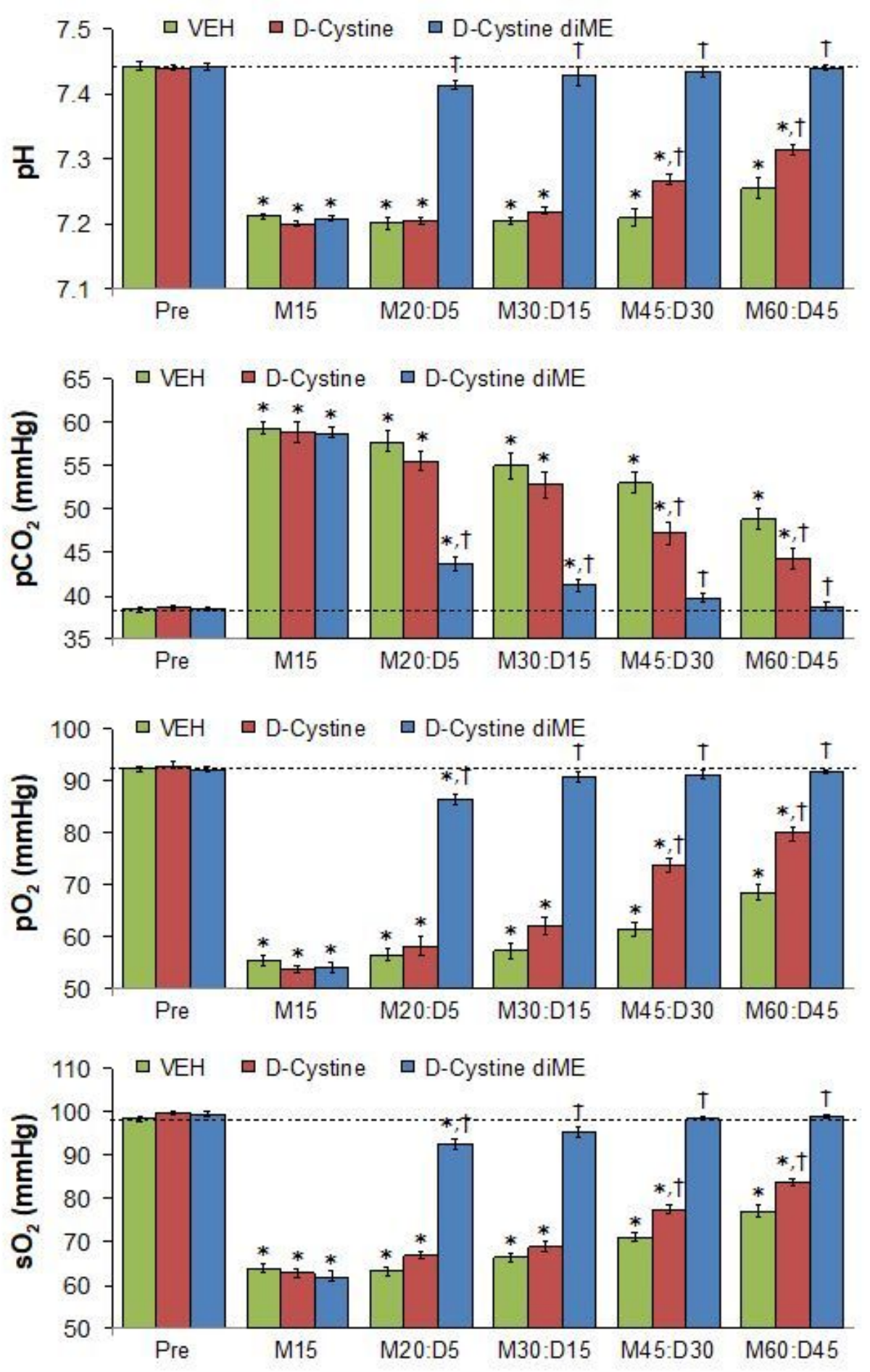

Figure 5

"See the Supplemental Files section for the complete figure caption". 


\section{Figure 6}

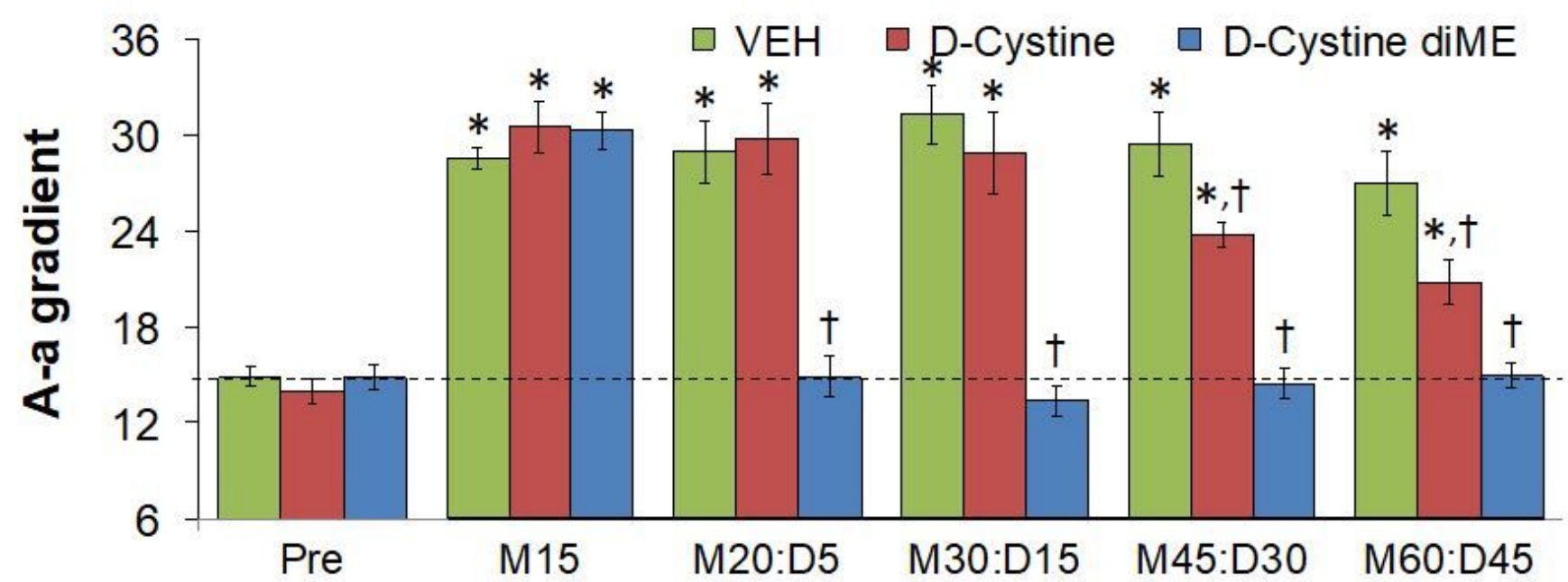

Figure 6

"See the Supplemental Files section for the complete figure caption".

Figure 7
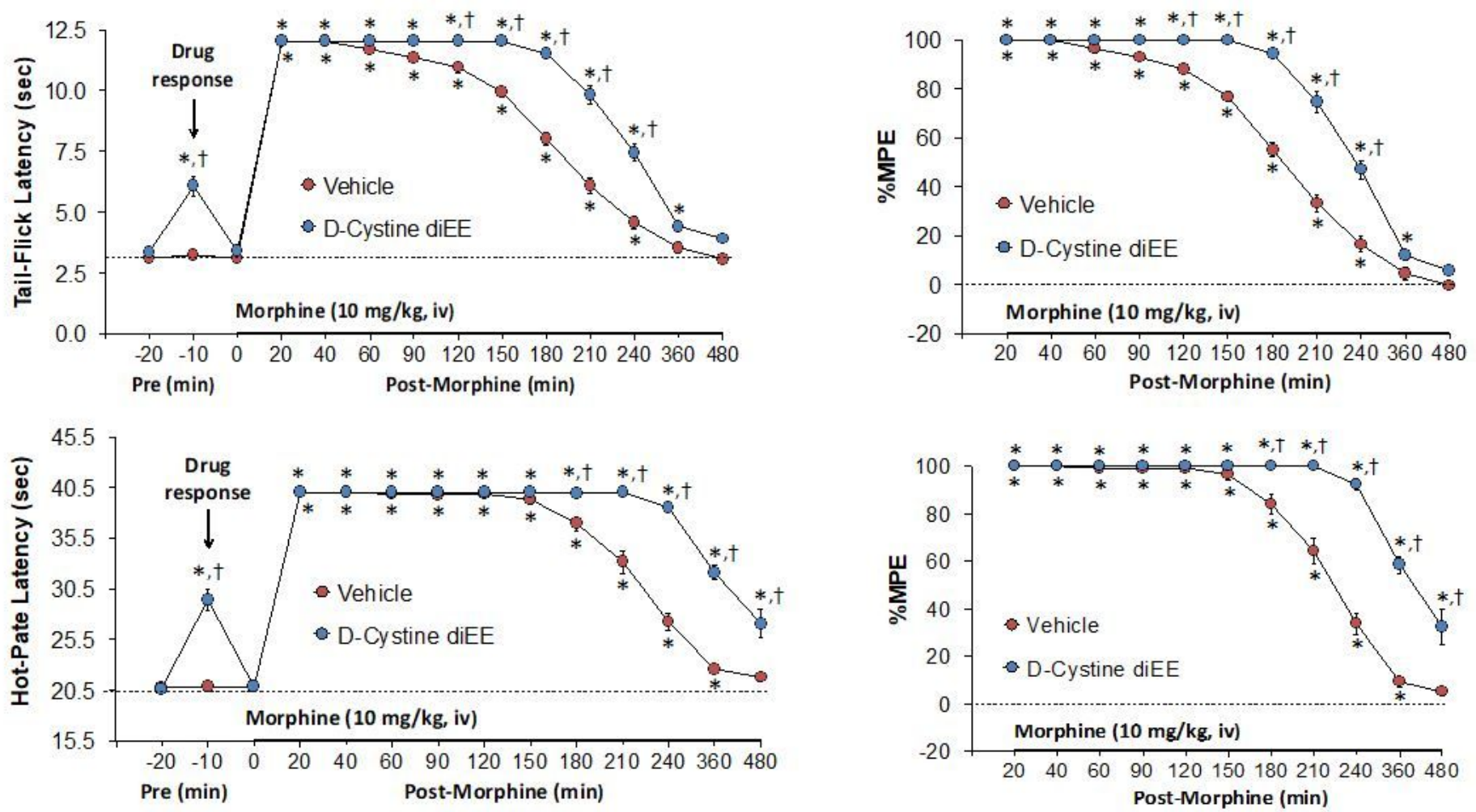

Figure 7

"See the Supplemental Files section for the complete figure caption".

\section{Supplementary Files}


This is a list of supplementary files associated with this preprint. Click to download.

- 2.SCIREPORTSSUDAXINEMSsubmissionFINALSUPPLEMENTR2.pdf

- FigureCaptions.docx 